\title{
Effect of Nursing Instructions on Reducing Selected Functional Gastrointestinal Disorders among Elderly Patients
}

\author{
Hanan Mohammed Essa ${ }^{(1)}$, Inshrah RoshdyMohammed ${ }^{(2)}$, Safaa R Mahmoud, ${ }^{(3)}$ Eman F. Abd El-khalik $^{(4)}$, OlaEzzat ${ }^{(5),}$ \\ 1. Demonstrator at Gerontological Nursing department, Faculty of Nursing, south valley University, \\ 2. Professor at Medical-Surgical Nursing Department, Faculty of Nursing, Minia University, \\ 3. Assist .Professor at Community Nursing Department, Faculty of Nursing, Assuit University, \\ 4. Assist .Professorr at Medical-Surgical Nursing Department, Faculty of Nursing, Minia University. \\ 5. lecturer at Gerontological Nursing department, Faculty of Nursing, Damanhour University,
}

\begin{abstract}
Background: Older people face many complex health problems such as constipation that affect older people's physical, psychological and social wellbeing. A nurse plays an important role in the management of functional gastrointestinal disorders and giving essential instructions for self-management to elderly patients. Aim of the study: To evaluate the effect of the nursing instructions on reducing the selected functional gastrointestinal disorders among elderly patients. Research design: Quasi-experimental (Pre-posttest). A consecutive sample in one year of one hundred elderly patients was included in this study. Setting: The current study was carried out at a geriatric home, geriatric club, and a gastrointestinal clinic at Qena, Egypt. two tools were utilized to collect data. First Tool: A Structured questionnaire sheet, personal data (age, gender, marital status level of education, etc.) Second Tool: The Patient Assessment of Constipation-Symptoms questionnaire. Results: There was a highly statistically significant difference in total mean average score and SD $(20.4 \pm 8.3,10.8 \pm 8.3)$ of constipation symptom severity during pre and post-nursing instructions implementation. $p$ value $\leq 0.05$. Conclusion implementing the nursing instructions regarding selected functional gastrointestinal disorders among elderly patients reflected a significant impact on patients outcomes of constipation. This significant difference justified the research hypothesis. Recommendations: continuous education and training are offered on a regular basis for elderly patients regarding gastrointestinal disorders, in addition to educational classes for elderly people about age-related changes that affect their gastrointestinal tract and elimination pattern without a feeling of shame or embarrassment to prevent complications. Encouragement to improve the elderly home foods menu to contain high fiber food such as vegetables and fruits to over com constipation problems.
\end{abstract}

Keywords: Elderly, Patients, Gastrointestinal disorders, Nursing instruction

\section{Introduction}

The changes that occur along the process of ageing in Gastrointestinal (GI) alteration in the elderly are common. (Igor Dumic, et al.,2019) Constipation is a common gastrointestinal disorder that negatively affects people's quality of life and burdens healthcare services worldwide. It is estimated that constipation affects between 6 and $18 \%$ of community-dwelling older adults and more than $60 \%$ of older adults in long-term care settings. In older adults, constipation is associated with frailty and decreased quality of life. Therefore, prevention and treatment of constipation should be a priority for nurses who look after older adults in long-term care settings. ( Murray, et al.,2020)

Constipation is defined as the presence of two or more of the following symptoms: straining to evacuate more than $25 \%$ of defecations, lumpy or hard stools in more than $25 \%$ of defecations, fewer than three spontaneous bowel movements per week,... etc. (lacy, et al.,2016)

Nurses are first-line professionals in long-term care settings, hence the importance of them implementing nonpharmacological interventions that improve constipation amongst older adults in long-term care settings. (White, et al.,2020) The gerontological nurse should educate the elderly on recognizing and responding to any urge to defecate, a regular daily routine, starting with light physical activity and the optimal times to have a bowel movement are soon after waking and after meals when the normal colon accentuates its motor activity. So, the nurse should educate the patients to try defecation first thing in the morning and in the post-prandial intervals to profit most from the gastro-colic reflex. Nurses

$P$ a g e $\mid 98$ can suggest a gradually increasing intake of fluids and fibres up to $30 \mathrm{~g} /$ day. This goal can be achieved by recommending the patient to integrate the diet with more fruits, vegetables, and nuts in addition to adding varying amounts of bran. (Lucak, et al.,2021)

The management of constipation in the elderly aims to relieve the symptoms associated with constipation, to restore normal bowel habits, which is defined as the passage of a soft, formed stool at least three times a week without straining, and to restore the quality of life without any significant adverse effects. There is no difference in the treatment of constipation between the elderly and younger adults. Treatment should be started with non-pharmacological approaches, including lifestyle changes, dietary changes, and physical activity. Within the pharmacological approaches, fibre and laxatives are the most commonly used as the initial treatment, according to several recent studies. (Lundberg, et al.,2020)

If lifestyle interventions are ineffective, medications are necessary; osmotic or stimulant laxatives are first-line therapy. These agents are at least as effective and less expensive than newer agents for treating chronic constipation in adults. (Chassagne, et al.,2017)It is advisable to start treatment with organic osmotic laxatives (polyethylene glycol with electrolytes, lactitol, or lactulose); if they are not effective, continue with inorganic osmotic laxatives (magnesium salts), lubricants (glycerin suppositories), and as the last step: stimulating laxatives (bisacodyl). This last group should be administered with caution since their long-term use can cause an atonic colon. (Serra, et al.,2017)

Hanan M., et al 


\section{Significance of the study}

Constipation is a chronic gastrointestinal condition that has a detrimental impact on people's quality of life and places a strain on healthcare systems across the world. Constipation affects between 6-18\%of community-dwelling older adults, as well as more than $60 \%$ of those in long-term care facilities. Constipation is linked to frailty and a lower quality of life in the elderly. (Murray, et al.,2020)

Functional constipation can have many different causes, ranging from changes in diet, physical activity, or lifestyle to primary motor dysfunctions due to colonic myopathy or neuropathy. (Sanaa \& Samah,2017)

the researcher went to the practical settings with the students and observed that a large number of elderly patients suffer from constipation for a long duration. For this reason, the researcher felt the importance of giving nursing instructions about lifestyle modifications for the elderly to help them control and prevent constipation.

\section{Aim of the Study}

The current study aims to:

- evaluate the effect of the nursing instructions on reducing the selected functional gastrointestinal disorders among elderly patients.

\section{Research Hypothesis}

- The frequency and severity of constipation among elderly patients post receiving the nursing instructions will be less than pre instructions.

\section{Subjects and Method}

\section{Study Design:}

Quasi-experimental (Pre-posttest) research design was utilized in the current study.

\section{Setting:}

This study was carried out at the Geriatric Home (Dar Al Hana), Geriatric Club, the outpatient clinic (Gastrointestinal clinic) at Qena \& University Hospital Qena Public Hospital- Qena Government - Egypt

\section{Subjects:}

The study sample was taken in one year (consecutive sample) who were 100 elderly patients.

\section{Tools of data collection}

The data of this study was collected by using two tools

\section{First Tool:}

Questionnaire sheet was developed by the researchers to collect the necessary data from the patients based on the literature review. It was collected by the researcher at the first interview. It was constituted of two main parts :

- Part (I): personnel characteristics: that includes (age, gender, phone number, marital status, level of education, ....etc.

- Part (II): Patient's medical data: that includes patients' awareness of risk factors for constipation.

2. Second Tool:(The Patient Assessment of ConstipationSymptoms (PAC-SYM) Questionnaire )

It was developed by (Frank, et al, 1999); to assess symptoms severity of chronic Constipation. It includes 12- symptoms it is divided into three subscales: abdominal (four items); rectal (three items); and stool (five items).

\section{Scoring System}

$>$ Items are scored on 5-point Likert scales ; they ranged from 0 to $4(0=$ meaning "symptoms absent , $1=$ meaning "mild , $2=$ meaning " moderate , $3=$ meaning " severe' and $4=$ meaning " very severe ).

$>$ A mean total score in the range of $0-4$ is generated by dividing the total score by the number of questions completed; the lower the total score, the lower the symptom burden.

$>$ A total score for the PAC-SYM ranged from zero, which means no constipation symptoms, to fortyeight, which means very severe constipation symptoms.

\section{Tools Validity and Reliability}

The two tools and scale content validity were done to identify the degree to which the used tools measure what was supposed to be measured. It was examined by a panel of five expert's opinions in the field of the study (Faculty of Nursing Medical-Surgical Nursing department) and necessary modifications were done. Tools were tested for content reliability using Alpha Cronbach's test. It was (0.91) for the second tool.

\section{Study Procedure}

The researcher contacted the studied subjects two days a week. Every session included an average of 2-3 elderly people. The researcher visited both hospital and the elderly home during the morning shift, but she went to the geriatric club in the evening. The researcher interviewed studied subjects who were admitted to hospitals clinics in the waiting room. They were informed by the researcher individually about the purpose and nature of the study through the interviewing method.

The first session: - the researcher began the pre-assessment baseline data by filling in the first tool (personal data and medical data)

The Second session: - for education and giving nursing instructions regarding constipation. This session contains two parts.

Part1:-Regard knowledge giving information about the meaning, signs \& symptoms, causes of constipation, ...etc. teach patients how to prevent constipation by educating them the dietary measures such as a high fibre diet and increased fluid intake, increased regular daily physical activity and regular toilet routine, ...etc.

Part 2: -Regard practice teaches the patient how to perform Brace Exercise and the good functional position when sitting on a toilet, (emulating a squat on the toilet) with the knees above the hips and the feet elevated.

The third and last session was conducted for evaluating the study subjects after giving the nursing instructions and after following them for three months. Each session lasted between (15 - 20) minutes. After each session, there were 10 minutes for discussion and giving feedback. Reinforcement of teaching was performed according to patients' needs to ensure their understanding. Each patient obtained a copy of the nursing instructions booklet which was prepared in the Arabic language. The researcher used pictures in it for illustration and 
more clarification of the studied subjects. The researcher followed -up with every patient weekly by telephone for three months to follow the bowel habits of each patient, ensure the patient's compliance with the instructions, and ask about any complaints.

\section{Pilot Study}

A pilot study was carried out on $10 \%$ (10 patients) of the total sample to test the feasibility, objectivity, and applicability of the data collection tools\& scale. The pilot study sample was not included in the study sample because some necessary modifications were done.

\section{Ethical Consideration}

* An official letter regarding the study's approval was obtained from the manager of the geriatric home (El Hana home), geriatric club, and gastrointestinal outpatient clinics to conduct the study; then the aim of the study was explained to them to obtain their cooperation.
* Patients were informed about the purpose, procedure, benefits, nature of the study, and follow-up, and they had the right to withdraw from the study at any time without any rationale. Strict confidentiality and anonymity of each subject were ensured through coding of all data and protecting the obtained data, then oral consents were obtained from subjects.

\section{Statistical Analysis}

The obtained data were reviewed, prepared for computer entry, coded, and analyzed by using SPSS (version 25). Descriptive statistics (frequencies, percentage, mean and standard deviation) were done. The Chi-square test and Fisher exact test were used to compare between the pre and post categories of constipation and personal data. A nonparametric test named the Wilcoxon signed ranks test was also used. Paired Samples Test, the independent sample T-test, the Pearson correlation test were used for testing the associations between continuous variables. It was considered significant when P-values were less than (0.05).

\section{Results:}

Table (1): Distribution of the study subjects according to their personal data $(n=100)$

\begin{tabular}{|c|c|c|}
\hline Personal data & No. & $\%$ \\
\hline \multicolumn{3}{|c|}{ Age: } \\
\hline - $60-74$ & 36 & 36.0 \\
\hline - $75-84$ & 46 & 46.0 \\
\hline - $\quad 85$-above & 18 & 18.0 \\
\hline Mean SD & \multicolumn{2}{|c|}{$77.3 \pm 7.5$} \\
\hline \multicolumn{3}{|c|}{ Sex: } \\
\hline Male & 41 & 41.0 \\
\hline - $\quad$ Female & 59 & 59.0 \\
\hline \multicolumn{3}{|c|}{ Marital status: } \\
\hline - $\quad$ Single & 3 & 3.0 \\
\hline - $\quad$ Married & 44 & 44.0 \\
\hline - $\quad$ Divorced & 9 & 9.0 \\
\hline - $\quad$ Widow & 44 & 44.0 \\
\hline \multicolumn{3}{|c|}{ Educational level: } \\
\hline - $\quad$ Illiterate & 48 & 48.0 \\
\hline - $\quad$ read and write & 29 & 29.0 \\
\hline - $\quad$ University & 23 & 23.0 \\
\hline \multicolumn{3}{|c|}{ Occupation before retirement: } \\
\hline - $\quad$ Farmer & 11 & 11.0 \\
\hline - $\quad$ Employee & 39 & 39.0 \\
\hline - $\quad$ Craftsman & 7 & 7.0 \\
\hline - $\quad$ Free works & 2 & 2.0 \\
\hline - $\quad$ Housewife & 41 & 41.0 \\
\hline \multicolumn{3}{|c|}{ Social life } \\
\hline - $\quad$ live alone & 22 & 22.0 \\
\hline - $\quad$ live with the family & 68 & 68.0 \\
\hline - $\quad$ live in an elderly home & 10 & 10.0 \\
\hline \multicolumn{3}{|c|}{ Residence: } \\
\hline - $\quad$ Rural & 53 & 53.0 \\
\hline - $\quad$ Urban & 47 & 47.0 \\
\hline
\end{tabular}

Table (1) shows that the mean age of the studied elderly was (77.3 \pm 7.5 years). Also, $59 \%, 44 \%$ and $41 \%$ of them were females, married, working as housewives respectively. Regarding education ,48\% were illiterate. Lastly, regarding social life, they lived with their families in the rural areas, constituting $(68 \%, 53 \%)$ respectively. 
Minia Scientific Nursing Journal (Print - ISSN 2537-012X) (Online - ISSN 2785-9797) Vol. (10) No. (1) December 2021

Table (2): Distribution of the study subjects according to their awareness regarding constipation risk factors

\begin{tabular}{|l|c|c|c|c|}
\hline $\begin{array}{l}\text { Patients awareness of risk factors regarding } \\
\text { constipation }\end{array}$ & \multicolumn{2}{|c|}{ Good awareness } & \multicolumn{3}{|c|}{ Bad awareness } \\
\hline Lake of mobility & No. & $\mathbf{\%}$ & \multicolumn{1}{|c|}{ No. } & \% \\
\hline Limited fluid intake & 81 & 81.0 & 19 & 19.0 \\
\hline Low-fiber diet & 88 & 88.0 & 12 & 12.0 \\
\hline Ignoring urge to defecate & 91 & 91.0 & 9 & 9.0 \\
\hline Fear of pain with defecation & 73 & 73.0 & 27 & 27.0 \\
\hline
\end{tabular}

Table (2): demonstrates that $91 \%, 88 \%$ and $81 \%$ have good awareness that a low fibre diet, limited fluid intake, and lack of mobility, respectively, are risk factors of constipation. $64 \%$ and $27 \%$ have poor awareness that fear of pain with defecation and ignoring the urge to defecate, respectively, are risk factors for constipation.

Table (3): comparison of overall total scores of constipation severity among studied subjects during pre and post nursing instructions implementation $(\mathbf{n}=89)$

\begin{tabular}{|c|c|c|c|c|c|c|}
\hline \multirow{2}{*}{$\begin{array}{l}\text { Constipation } \\
\text { symptoms }\end{array}$} & \multicolumn{2}{|c|}{ Pre } & \multicolumn{2}{|c|}{ Post } & \multirow[t]{2}{*}{$\begin{array}{c}\text { Test of } \\
\text { significance }\end{array}$} & \multirow[t]{2}{*}{ P-value } \\
\hline & Frequency & Percent & Frequency & Percent & & \\
\hline Mild & 4 & 4.5 & 61 & 68.5 & \multirow{5}{*}{$\begin{array}{c}\text { Wilcoxon Signed } \\
\text { Ranks Test } \\
-7.551\end{array}$} & \multirow[t]{5}{*}{0.000} \\
\hline Moderate & 52 & 58.4 & 20 & 22.5 & & \\
\hline Sever & 33 & 37.1 & 8 & 9.0 & & \\
\hline Very sever & 0 & 0 & 0 & 0 & & \\
\hline Total & 89 & 100 & 89 & 100 & & \\
\hline Mean \pm SD & \multicolumn{2}{|c|}{$20.4 \pm 8.3$} & \multicolumn{2}{|c|}{$10.8 \pm 8.3$} & $\begin{array}{c}\text { Paired samples } \\
\text { T-test } \\
11.73\end{array}$ & 0.001 \\
\hline
\end{tabular}

Table (3): represents that there is a highly statistically significant difference in total mean average score and SD (20.4 $\pm \mathbf{8 . 3}$, $\mathbf{1 0 . 8} \pm \mathbf{8 . 3}$ ) of constipation symptom severity during pre and post nursing instructions implementation. $\mathbf{p}$-value $\leq \mathbf{0 . 0 5}$

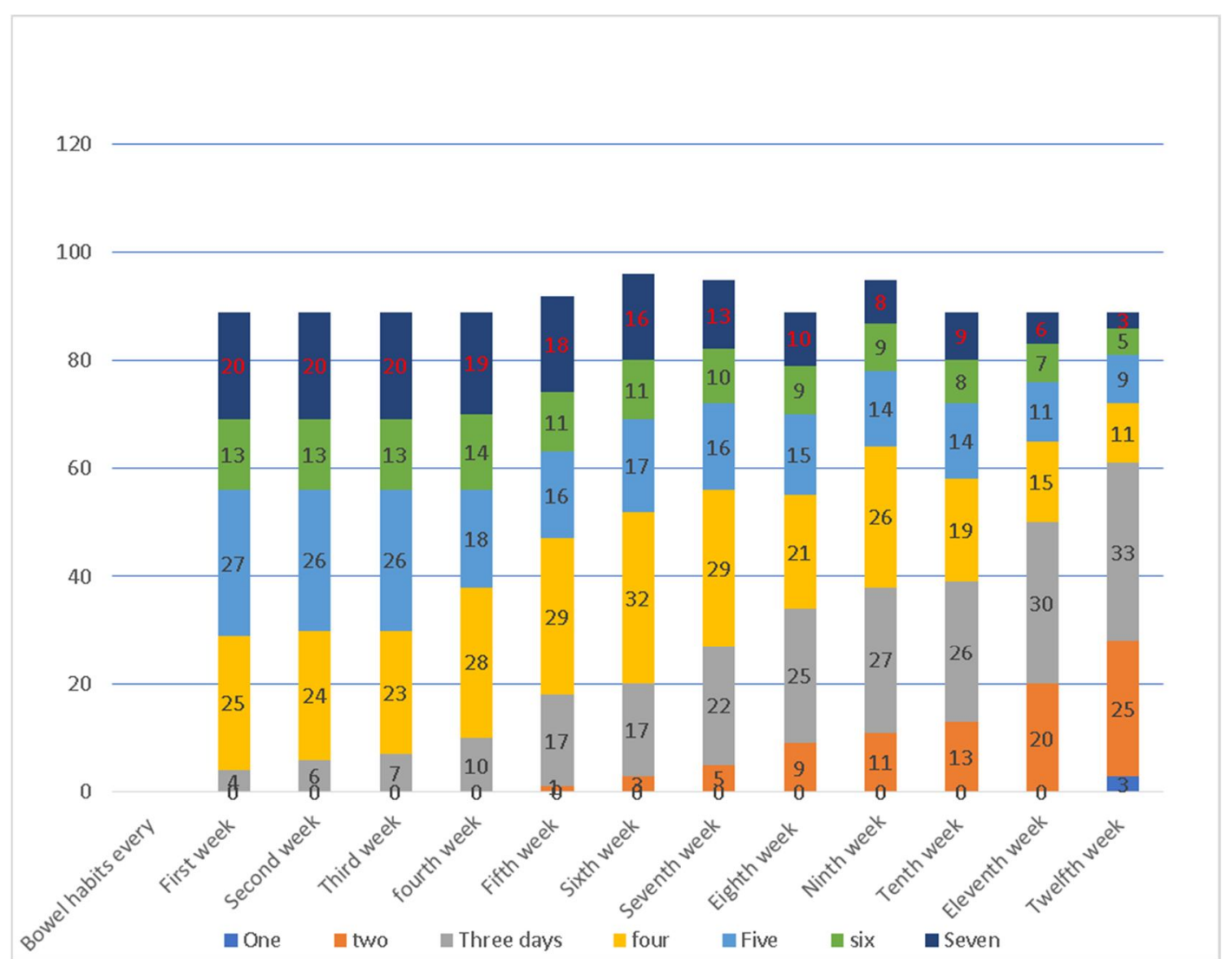

Figure (1): distribution of the defecation frequency of the studied subjects during the three months after nursing instructions implementation for constipated subjects. $(n=89)$

Figure (1): clarifies that in the first week there were only four subjects who defecated every three days, while twenty-five subjects defecated every four days, twenty-seven subjects defecated every five days, thirteen subjects defecated every six days and twenty subjects defecated every seven days. in the $6^{\text {th }}$ week and following, there were three subjects who defecated every two days, 
seventeen subjects defecated every three days, thirty-two subjects defecated every four days, seventeen subjects who defecated every five days, eleven subjects defecated every six days, and sixteen subjects defecated every seven days. But in the $12^{\text {th }}$ week, three subjects who defecated every day, twenty-five subjects defecated every two days, thirty-three subjects defecated every three days, eleven subjects defecated every four days, nine subjects were defecated every five days, five subjects defecated every six days, and only three subjects defecated every seven days.

Table (4): correlation among the studied subjects between constipation severity and their data post nursing instruction implementation after three months

\begin{tabular}{|c|c|c|c|c|c|c|}
\hline \multirow{2}{*}{$\begin{array}{l}\text { Study personal } \\
\text { data }\end{array}$} & \multicolumn{6}{|c|}{ Constipation severity } \\
\hline & No & Mild & Moderate & sever & Very sever & $\begin{array}{l}X^{2} \\
\text { PValue }\end{array}$ \\
\hline \multicolumn{7}{|l|}{ Age } \\
\hline $60-74$ & 0 & 36 & 0 & 0 & 0 & \multirow{3}{*}{$\begin{array}{c}53.003 \\
\mathbf{0 . 0 0 1}\end{array}$} \\
\hline $75-84$ & 4 & 23 & 15 & 4 & 0 & \\
\hline 85 -above & 7 & 2 & 5 & 4 & 0 & \\
\hline \multicolumn{7}{|l|}{ sex } \\
\hline Male & 3 & 25 & 11 & 2 & 0 & \multirow{2}{*}{$\begin{array}{l}3.324 \\
0.334 \\
\end{array}$} \\
\hline Female & 8 & 36 & 9 & 6 & 0 & \\
\hline \multicolumn{7}{|l|}{ Marital status } \\
\hline Single & 2 & 1 & 0 & 0 & 0 & \multirow{4}{*}{$\begin{array}{c}12.876 \\
\mathbf{0 . 1 6 8}\end{array}$} \\
\hline Married & 3 & 29 & 8 & 3 & 0 & \\
\hline Divorced & 1 & 5 & 3 & 0 & 0 & \\
\hline Widow & 5 & 26 & 9 & 5 & 0 & \\
\hline \multicolumn{7}{|l|}{ Educational level } \\
\hline Illiterate & 8 & 24 & 11 & 5 & 0 & \multirow{5}{*}{$\begin{array}{c}22.264 \\
\mathbf{0 . 0 3 5}\end{array}$} \\
\hline Read and write & 3 & 8 & 2 & 2 & 0 & \\
\hline Primary school & 0 & 0 & 2 & 0 & 0 & \\
\hline Secondary school & 0 & 9 & 2 & 1 & 0 & \\
\hline University & 0 & 20 & 3 & 0 & 0 & \\
\hline
\end{tabular}

$\mathbf{P} \leq \mathbf{0 . 0 5}$

Table (4): illustrates that there is a highly statistically significant correlation between the constipation severity and the study subjects' age and educational level $\mathbf{p - v a l u e ~} \leq \mathbf{0 . 0 5}$. while there is no statistically significant correlation between constipation and the study subjects' sex and marital status.

\section{Discussion}

Functional gastrointestinal disorders (FGIDs) are disorders with chronic or recurrent symptoms attributable to the gastrointestinal tract (GI) in the absence of organic disease that can be identified by routine investigations. Diagnosis of FGIDs is mainly based on the patient's symptoms, interpretation , and reporting. Although FGIDs do not lead to an increase in mortality, they cause significant morbidity.

(Van Oudenhove, et al.,2016)

Constipation is a common gastrointestinal disorder that negatively affects the elderly's quality of life and burdens healthcare services worldwide. It is estimated that constipation affects between 6 and $18 \%$ of community-dwelling older adults and more than $60 \%$ of older adults in long-term care settings. (Dobarrio-Sanz, et al.,2020)

The current study aims to evaluate the effect of the nursing instructions on reducing the selected functional gastrointestinal disorders among elderly patients.

The first section will be devoted to the personal data of the study subjects. The results of the current study revealed that nearly one-half of the study participants were aged between 75-84 years old, with the mean average age \pm SD was $(77.3 \pm 7.5)$ years. Then they complained of constipation, which may be attributed to the ageing process, physiological changes, health status, physical inactivity, and reduced rate of colon peristalsis. Then they complained of constipation
This finding approximately goes along the same line as with the study done by Inkaya, \& Tuzer( 2020), on 60 elderly people in Ankara, Turkey, they found that about threequarters of the study participants' mean age ( 72 years old for the control group and 79 years old for experimental group). These results of the current study disagree with the study done by Hassan, et al. (2021), who found that the majority of the studied sample aged 60-70years

The results of the current study revealed that nearly two-thirds of the study participants were females. This may be due to the slower movement of a female, which leads to slower absorption of food through a woman's intestines, and the effects of female hormones on the GI tract, so that constipation prevalence was higher in women.

This finding agreed with the study done by Okuyan \& Bilgili (2019), on 220 older adults and found that nearly two-thirds of the study participants were females. These findings didn't match with Farg et al. (2020), who reported that more than half were male.

Regarding educational level, the present study findings demonstrated that nearly one-half of the study participants were illiterate, This may be rationalized as in the past, there was no interest in education and fewer opportunities for education in upper Egypt at Qena. So, illiteracy was common among the elderly, and that led to a lack of health awareness. 
This finding is supported by Saad \& Hassanein (2019), who conducted a study on 53 elderly patients in Mansoura, Egypt and found that about one-half of the study participants weren't able to read or write. This finding didn't match with Abd El-Fatah, et al. (2021), who found that more than a quarter of the constipated elderly were illiterate.

The participating sample findings show that more than one-half of the study participants lived in rural areas. This may be due to the distance and shortage of health services from rural areas, and this may cause constipation more in rural areas than in urban ones, due to the lack of awareness regarding healthy habits.

This finding is supported by Abd Allah et al.(2013), who reported that nearly two-thirds of the studied group resided in rural areas. On the contrary, Zhang et al.(2015), found that in the Beijing region, the elderly population in urban areas had a higher prevalence of constipation than in rural areas

The second section: Regarding the distribution of the study subjects according to their awareness of constipation risk factors.

The result of the current study shows that pre-nursing instructions implementation showed that the majority of the study subjects had good awareness that low fibre diets and limited fluid intake are risk factors for constipation.

This is maybe due to about half of the study subjects being read and write secondary school and have a university degree, so they can use mass media and social media and they can educate themselves and understand the information and knowledge from it.

The results of the current study revealed that about two-thirds and one-third of the study participants fear pain during defecation, and they ignore the urge to defecate, which leads to constipation for them. This finding disagrees with the study done by Vollebregt, et al. (2020), on 4,027 patients, which found that more than one-fifth of the study participants had poor awareness that ignoring the urge to defecate is one of the risk factors of constipation.

The third section: comparison of overall total scores of constipation severity among studied subjects during pre and post-nursing instruction implementation. The results of the current study revealed that there is a highly statistically significant improvement in the total mean average score and SD $(\mathbf{2 0 . 4} \pm \mathbf{8 . 3}, \mathbf{1 0 . 8} \pm \mathbf{8 . 3})$ of constipation symptom severity during pre and post nursing instruction implementation (pvalue $\leq \mathbf{0 . 0 5}$ ). These findings may be due to the effect of the current study's nursing instructions and practices that have been taught by the researcher and the patient's compliance with implementing these instructions.

This finding is supported by Yilmaz, et al. (2017), who conducted a descriptive study on 309 patients aged 65 and above and found that nonpharmacological interventions such as increasing liquid intake, adding fibrous food to the diet, and increasing physical activity are important for treating constipation and decreasing its severity among the elderly. This finding was also supported by the results of a study done by Hassan, et al.(2021), on 84 elderly people at the Sohag geriatric club in Egypt, and the study revealed that there was a highly statistically significant improvement in the severity of constipation before and after the application of the nursing intervention. p-value (0.000). On the other hand, another study that disagreed with our study done by Moustafa, et al. (2019), found that there were no statistical differences between the severity of constipation before and after the program among the elderly.

Fourth section: following up on the constipation frequency of study subjects (bowel assessment) for three months. The result clarifies that in the $6^{\text {th }}$ week and by following, there were three subjects from (89) defecated every two days, seventeen subjects defecated every three days, thirty-two subjects defecated every four days, seventeen defecated every five days, eleven subjects defecated every six days, and sixteen subjects defecated every seven days. But in the $12^{\text {th }}$ week, three subjects from (89) defecated every day, twenty-five subjects defecated every two days, thirty-three subjects defecated every three days, eleven subjects defecated every four days, nine subjects defecated every five days, five subjects defecated every six days, and only three subjects defecated every seven days.

This result is due to the positive effect of the current study's nursing instructions that affect their attitude and change in their attitudes and practises regarding heir bowel habits. This result is to some extent similar to the study conducted by Karima. et al. (2018), according to elimination pattern; the study illustrated that the majority of the study group had an elimination pattern every day compared with a minority of the control group post-program. This result was supported by Abd Elgafar and Abd Elgaphar(2017), who stated that the majority of the study group (90\%) compared with the minority of the control group ( $8 \%$ ) had an elimination pattern every 1-2 days post-program with a highly statistically significant difference.

Fifth section: correlation among the studied subjects between constipation severity and their data post nursing instruction implementation after three months. Current study findings display that there is a highly statistically significant correlation between constipation severity and the study subjects' age and educational level (p-value $\leq \mathbf{0 . 0 5}$ ).

This result may be due to age greater than 65 years is also associated with dentition that is more often incomplete, wearing dentures, and difficulty chewing food, forcing subjects to choose low-fiber foods. These results could be explained by the fact that educated people have easier access to information via the media and the internet. This explains the relationship between constipation and education

This finding is with that of Sehonou, et. al. (2018), who found that there was a statistically significant relationship between age and constipation $(p=0.049)$, with a peak of the constipated population in the age group of 60 and over. This study contradicts that of Mansouri et al. (2018), who reported that there was no significant relationship between constipation and age. Our results are identical to those of Ndam, et al. (2017), in North America who reported that a low level of education was a risk factor for constipation. This result contradicted a study done by Sehonou, et al. (2018), who didn't find the relation between the level of education and constipation.

\section{Conclusion}

Implementing the nursing instructions regarding selected functional gastrointestinal disorders among elderly patients revealed a significant impact on patients' outcomes of constipation. The frequency and severity of constipation results among the studied subjects decreased when implementing the nursing instructions than before implementing these nursing instructions, and this significant difference justified the research hypothesis. 


\section{Recommendations}

Based on the results, the study recommended that:

- A continuous education and training program based on evidence-based practice for staff nurses is planned and offered on a regular basis regarding elderly patients who have gastrointestinal changes and disorders.

- Written Arabic booklets, brochures, and posters which include instructions about constipation must be provided at any health care setting that contacts elderly people and their caregivers.

- Educational classes for elderly people about agerelated changes that affect their gastrointestinal tract and elimination patterns without a feeling of shame or embarrassment to prevent complications.

- Encouraging to improve the elderly home food menu to contain high-fibre food such as vegetables and fruits.

- Replication of the current study on a larger probability sample from different geographical areas in Egypt is needed to obtain more generalizable data.

- Replication of the current study with another relevant variable.

\section{References}

(1) Abd Allah, Eman Shokry, Heba Ali Allah Ibrahim, and Howaida Henry Fahmy. (2013)."Effect of nursing intervention on constipation among elderly in Zagazic city Sharkia governorate-Egypt." Journal of American Science $9.3 \mathrm{~s}$

(2) Abd El Gafar, Sanaa Ibrahim, and Samah M. Abd Elgaphar (2017). Impact of Performing Bowel Educational Guidelines on Preventing Constipation among Bed Ridden Patients IOSR Journal of Nursing and Health Science (IOSR-JNHS) -ISSN: 2320-1959. pISSN: 2320-1940 Volume 6, Issue 3 Ver. V (May - June 2017), PP 59-66

(3) Abd El-Fatah, S. H., Fahmy, H. M., \& Abd Al-fatah W. $\mathrm{H},(2021)$ Effect of Nursing Intervention on Severity of Constipation among Elderly People at Sohag Geriatric Club, Egypt. Journal of Health Care, EJH, 12(1).

(4) Chassagne, P., Ducrotte, P., Garnier, P., \& MathiexFortunet, H. (2017). Tolerance and long-term efficacy of polyethylene glycol 4000 (Forlax ${ }^{\circledR)}$ compared to lactulose in elderly patients with chronic constipation. The journal of nutrition, health \& aging, 21(4), 429-439.

(5) Dobarrio-Sanz, I., Hernández-Padilla, J. M., LópezRodríguez, M. M., Fernández-Sola, C., Granero-Molina, J., \& Ruiz-Fernández, M. D. (2020). Non-pharmacological interventions to improve constipation amongst older adults in long-term care settings: A systematic review of randomised controlled trials. Geriatric Nursing

(6) Farg K., Ibrahim E., \& Bagdady G., (2020). Effect of Health Educational Program About Constipation On Elderly Quality of Life, IOSR Journal of Nursing and Health Science (IOSR- JNHS), 9 (1), 57-65

(7) Frank L, Kleinman L, Farup pC, Taylor L, Taylor L, Miner PJr . (1999): Psychometric validation of constipation symptoms assessment questionnaire. Scand J Gastroenterology .34(9): 870

(8) Hassan Abd El-Fatah, S., Mohamed Fahmy, H., \& Hassan Abd Alfatah, W. (2021). Effect of Nursing Intervention on Severity of Constipation among Elderly People at Sohag Geriatric Club, Egypt. Egyptian Journal of Health Care, 12(1), 73-83.

(9) Igor Dumic, Terri Nordin, Mladen Jecmenica, Milica Stojkovic Lalosevic, Tomica Milosavljevic, and Tamara Milovanovic, (2019), Gastrointestinal Tract Disorders in
Older Age, Can J Gastroenterol Hepato; 2019: 6757524. DOI: $10.1155 / 2019 / 6757524$

(10) Inkaya, B., \& Tuzer, H. (2020). Effect of Reflexology on the Constipation Status of Elderly People. Yonago Acta Medica, 63(2), 115-

(11) Karima Fuad Elshamy, Walaa Nasreldin Othman, Asmaa Ahmed Hassan. (2018). Effect of Implementing Nursing Program on Minimizing Constipation among Immobilized Patients at Mansoura University Hospitals. Nat Sci;16(9):103-110]. ISSN 1545-0740 (print); ISSN 23757167 (online). http://www.sciencepub.net/nature.15.doi:10.7537/marsnsj1 6091815.

(12) Lacy, B. E., Mearin, F., Chang, L., Chey, W. D., Lembo, A. J., Simren, M., \& Spiller, R. (2016). Bowel disorders. Gastroenterology, 150(6),13931407.e5.doi:10.1053/j.gastro.2016.02.031

(13) Lucak, S., Lunsford, T. N., \& Harris, L. A. (2021). Evaluation and Treatment of Constipation in the Geriatric Population. Clinics in Geriatric Medicine, 37(1), 85-102

(14) Lundberg, V., Boström, A. M., Gottberg, K., \& Konradsen, H. (2020). Healthcare Professionals' Experiences of Assessing, Treating and Preventing Constipation Among Older Patients During Hospitalization: An Interview Study. Journal of Multidisciplinary Healthcare, 13, 1573.

(15) Mansouri, A., Shahraki-Vahed, A., Shadadi, H., Sanchooli, H. N., \& Arbabisarjou, A. (2018). The effect of prune on the severity of constipation in elderly women. Bali Medical Journal, 7(1), 141-145

(16) Moustafa Tag El-Melook Saad1, Eman Baleagh Meawad2, Amira Ahmed Hassanein. ( 2019), International Journal of Novel Research in Healthcare and Nursing Vol. 6, Issue 1, pp: (148-164), Month: January, Available at: www.noveltyjournals.com

(17) Murray, H. B., $\quad$ Flanagan, R., $\quad$ Banashefski, B., Silvernale, C. J., Kuo, B., \& Staller, K. (2020). Frequency of eating disorder pathology among patients with chronic constipation and contribution of gastrointestinal-specific anxiety, Clinic Gastroenterol Hepatol 10.1016/j.cgh.2019.12.030

(18) Ndam, A.N., Melchior, C., Gourcerol, G., Leroi, A.M. and Ducrotté, P. (2017).Constipation Fonctionnelle Chronique de L'Adulte: Quelles Nouveautés? Hépato-Gastro \& Oncologie Digestive, 24, 667-677.

(19) Okuyan, C. B., \& Bilgili, N. (2019). Effect of abdominal massage on constipation and quality of life in older adults: A randomized controlled trial. Complementary therapies in medicine, 47, 102219.

(20) Saad, M. T. E. M., Meawad, E. B., \& Hassanein, A. A (2019). Effect of Nursing Intervention program on Gastrointestinal Tract Problems among Elderly Patients undergoing Chemotherapy.

(21) Sanaa Ibrahim Abd El Gafar and Samah M.Abd Elgaphar,(2017). Impact of Performing Bowel Educational Guidelines on Preventing Constipation among Bed Ridden Patients

(22) Sehonou, J., Kpossou, A. R., Sokpon, C. N. D. M., Cataria, H., Azandjeme, C., \& Vignon, K. R. (2018). Functional Constipation in the General Population in Cotonou: Prevalence and Associated Socio-Demographic Factors. Open Journal of Gastroenterology, 8(09), 306.

(23) Serra, J., Mascort-Roca, J., Marzo-Castillejo, M., Aros, S. D., Santos, J. F., Rubio, E. R. D., \& Manrique, F. M. (2017). Clinical practice guidelines for the management of constipation in adults. Part 2: Diagnosis and treatment. Gastroenterología y Hepatología (English Edition), 40(4), 303-316.

(24) Van Oudenhove L, Levy RL, Crowell MD, et al.( 2016), Biopsychosocial aspects of functional gastrointestinal disorders: how central and environmental processes 
contribute to the development and expression of functional gastrointestinal disorders. Gastroenterology;150:13551367, e2.

(25) Vollebregt, P. F., Wiklendt, L., Dinning, P. G., Knowles, C. H., \& Scott, S. M. (2020). Coexistent fecal incontinence and constipation: A cross-sectional study of 4027 adults undergoing specialist assessment. EClinicalMedicine, 27, 100572.

(26) White, E. M., Aiken, L. H., Sloane, D. M., \& McHugh, M. D. (2020). Nursing homework environment, care quality, registered nurse burnout, and job dissatisfaction. Geriatric
Nursing,

41(2),

doi:10.1016/j.gerinurse.2019.08.007

(27) Yilmaz, Cemile Kutmec, and Guler Duru Asiret. (2017): "Identifying the Constipation Levels of Older People and their Interventions for Recovery." International Journal of Caring Sciences 10.3:1605-1614.

(28) Zhang, M., Yang, X. J., Zhu, H. M., Tang, Z., Li, B. Y., \& Zhao, D. D. (2015). Epidemiological study of elderly constipation in Beijing. World journal of gastroenterology, 21(47), 13368. 